\title{
Contabilidade de custos vs. contabilidade de ganhos: respostas às exigências da produção enxuta
}

\author{
Cost accounting vs. throughput accounting: \\ answer to the lean production's demands
}

\author{
José Antonio de Queiroz ${ }^{1}$ \\ Antonio Freitas Rentes ${ }^{2}$
}

\begin{abstract}
Resumo: A produção enxuta tem provocado mudanças significativas nas empresas, mudanças estas que não vêm sendo acompanhadas pelos sistemas de gestão econômica, desenvolvidos sobre pressupostos equivocados da produção em massa que defendem que as otimizações locais isoladas resultam na otimização global da empresa. Deste modo, pode-se afirmar que a contabilidade de custos não é capaz de prover as informações necessárias à correta tomada de decisão nas empresas enxutas. Por outro lado, constata-se uma coerência entre os princípios da produção enxuta e os pressupostos que sustentam a contabilidade de ganhos da Teoria das Restrições. Sendo assim, o objetivo deste artigo é apresentar argumentos que respaldem estas afirmações, bem como justifiquem a necessidade da utilização da contabilidade de ganhos como base teórica para a proposta de um método de gestão econômica para a produção enxuta.
\end{abstract}

Palavras-chave: Produção enxuta. Contabilidade de custos. Contabilidade de ganhos.

\begin{abstract}
Lean production has provoked significant changes in companies. These changes have not being followed by the economic management systems, which are developed based on mistaken assumptions made by mass production which argues that isolated local optimizations can lead to the global optimization of the company. In this way, it can be affirmed that cost accounting cannot provide the necessary information for decision making in lean companies. On the other hand, consistency is evidenced between the principles of the lean production and the assumptions that support the throughput accounting of the Theory of Constraints. Therefore, the objective of this article is to present arguments that corroborate these assertions and justify the necessity for the use of the throughput accounting as a theoretical basis for the proposal of an economic management method for lean production.
\end{abstract}

Keywords: Lean production. Cost accounting. Throughput accounting.

\section{Introdução}

\subsection{Problema}

Segundo Rother e Shook (1999), a produção enxuta tem provocado mudanças significativas nas empresas. Observa-se, porém, que tais mudanças não vêm sendo acompanhadas pelos sistemas de gestão econômica, desenvolvidos sobre pressupostos equivocados da produção em massa que defendem que as otimizações locais isoladas conduzem à otimização global da empresa. De acordo com Goldratt (1991), constata-se, diante destas mudanças, que a contabilidade de custos, síntese maior dos sistemas de gestão econômica voltados para a produção em massa, não é capaz de prover as informações necessárias à correta tomada de decisão nas empresas enxutas. Ainda segundo Goldratt (1991), a incapacidade da contabilidade de custos em apoiar o processo decisório nas empresas enxutas ocorre, sobretudo, pelo fato de ela considerar todos os recursos como igualmente importantes, sejam eles restrições ou não restrições, o que é incorreto, como muito bem demonstra a contabilidade de ganhos, braço contábil da Teoria das Restrições. De acordo com Corbett Neto (1997), para a contabilidade de ganhos, toda empresa é um sistema e todo sistema tem pelo menos uma restrição que determina

\footnotetext{
${ }^{1}$ Recém-doutor (Doutorado financiado pela Capes), Instituto de Ciências Sociais Aplicadas - ICSA, Universidade Federal de Alfenas - UNIFAL-MG, Campus Varginha, Avenida Alfredo Braga de Carvalho, 303, Parque Industrial JK, CEP 37062-440, Varginha, MG, Brasil, E-mail: ja.queiroz@uol.com.br

2 Departamento de Engenharia de Produção, Escola de Engenharia de São Carlos - EESC, Universidade de São Paulo - USP, Avenida do Trabalhador Sãocarlense, 400, CEP 13566-590, São Carlos, SP, Brasil, E-mail: rentes@sc.usp.br
}

Recebido em 19/2/2008 — Aceito em 2/3/2010

Suporte financeiro: Capes. 
sua capacidade e limita seu desempenho, e, sendo assim, é necessário que a empresa identifique as suas restrições e decida como explorá-las, de tal modo que as restrições e as não restrições sejam tratadas de modo diferente, estando as não restrições subordinadas às restrições. Ainda segundo Corbett Neto (1997), a implicação do tratamento diferenciado entre as restrições e as não restrições é que o pressuposto da contabilidade de custos de que as otimizações locais isoladas conduzem à otimização global da empresa é substituído pelo pressuposto da contabilidade de ganhos que sempre julga o impacto de qualquer ação local sobre o resultado global da empresa.

\subsection{Relevância}

De acordo com Goldratt (1991) e Corbett Neto (1997), o pressuposto equivocado de que as otimizações locais isoladas conduzem à otimização global da empresa acaba se refletindo diretamente nos medidores de eficiência das máquinas. Todos tentam maximizar a eficiência de todas as máquinas, não podendo haver ociosidade em lugar ou máquina alguma. No entanto, uma empresa sempre tem recursos com menor capacidade, o que faz com que a procura por elevadas eficiências locais isoladas só conduza ao aumento dos estoques de matériasprimas, materiais em processo e produtos acabados, o que alimenta a superprodução e fere os princípios da produção enxuta. Ainda segundo Goldratt (1991) e Corbett Neto (1997), os recursos não restrição não podem trabalhar mais devagar que a restrição, pois, assim, ela pararia e o desempenho do sistema seria afetado negativamente. Por outro lado, não devem trabalhar mais rápido que a restrição, pois, não estariam aumentando a produção do sistema, mas, somente, o estoque em processo. Para aumentar o desempenho do sistema, deve-se fazer com que as não restrições trabalhem no passo das restrições, nem mais rápido e, também, nem mais devagar.

Confrontando os pressupostos do mundo dos custos e do mundo dos ganhos com os princípios enxutos, conclui-se que existe uma maior e melhor adequação da contabilidade de ganhos à produção enxuta. Esta maior e melhor adequação da contabilidade de ganhos à produção enxuta deve-se, sobretudo, pelo fato da contabilidade de ganhos desestimular o maior dos desperdícios combatidos pela produção enxuta, que é a superprodução. $\mathrm{O}$ desestímulo à superprodução na contabilidade de ganhos decorre do fato desta, ao contrário da contabilidade de custos, que vê no aumento dos volumes de produção, tanto das restrições quanto das não restrições, uma forma de reduzir os custos unitários, considerar que material produzido e não vendido não aumenta o ganho da empresa, causando somente aumentos nos seus inventários e nas suas despesas operacionais. Assim sendo, a relevância deste artigo encontra respaldo na medida em que a falta de habilidade em administrar suas restrições faz com que as empresas enxutas que continuam aplicando a contabilidade de custos não consigam avaliar adequadamente os seus resultados, comprometendo, até mesmo, a própria continuidade da implementação enxuta.

\subsection{Objetivos}

O objetivo é confrontar os pressupostos do mundo dos custos e do mundo dos ganhos quanto às adequações destes às exigências impostas pelos sistemas de lean manufacturing, estabelecendo as bases teóricas necessárias à criação de um método de gestão econômica adequado à realidade e às necessidades dos sistemas produtivos enxutos.

\section{Produção enxuta}

Segundo Rother e Shook (1999), produção enxuta é o conjunto das melhores práticas que cruzam as fronteiras departamentais com o objetivo de eliminar desperdício e criar valor.

Araújo (2004) cita que Hines e Taylor (2000) classificam as atividades em três grandes grupos:

1. atividades que efetivamente criam valor às empresas;

2. atividades que não criam valor, mas que ainda são necessárias; e

3. atividades que não criam valor, e que também não são mais necessárias.

A Figura 1 apresenta a participação de cada grande grupo de atividade no montante.

Observe que as atividades que não criam valor representam 95\% do montante total, sendo 35\% de atividades do grupo 2 e $60 \%$ de atividades do grupo 3.

Para Rother e Shook (1999), o foco da produção enxuta são as atividades tipos 2 e 3 . As atividades do tipo 3 não são mais necessárias e devem ser eliminadas imediatamente, enquanto que as atividades do tipo 2 devem ser eliminadas tão logo seja

Atividades que criam valor: $5 \%$ Atividades que não criam valor: 95\%

Figura 1. Composição das atividades segundo Hines e Taylor (2000). Fonte: Araújo (2004, p. 33). 
possível às empresas. A Figura 2 apresenta a diferença de foco entre as produções em massa e enxuta.

Segundo Ghinato (2000), Taiichi Ohno, o criador do Sistema Toyota de Produção, propôs que os desperdícios ou perdas fossem classificados em sete grupos:

- O primeiro grupo de desperdício é o das perdas por superprodução, que são as mais danosas, uma vez que têm a propriedade de esconder as outras, e podem ser divididas em dois subgrupos. O primeiro subgrupo é o das perdas por superprodução por quantidade, as quais ocorrem quando a produção é realizada além da quantidade programada e, deste modo, os produtos ficarão estocados aguardando a ocasião de serem processados ou consumidos pelas etapas posteriores. O segundo subgrupo é o das perdas por superprodução por antecipação, as quais ocorrem quando a produção é realizada antes do momento necessário e, novamente, os produtos ficarão estocados aguardando a ocasião de serem processados ou consumidos pelas etapas posteriores.

- O segundo grupo de desperdício é o das perdas por espera, as quais ocorrem sob a forma de esperas desnecessárias, e podem ser divididas em três subgrupos. O primeiro subgrupo é o das perdas por espera do processo, as quais ocorrem quando o lote posterior aguarda o término do processamento que está sendo executado no lote anterior. O segundo subgrupo é o das perdas por espera do lote, as quais ocorrem quando um produto aguarda o término do processamento que está sendo executado nos demais produtos de seu lote. O terceiro subgrupo é o das perdas por espera do operador, as quais ocorrem quando o operador permanece junto à máquina para acompanhar o processamento do início ao fim.

- O terceiro grupo de desperdício é o das perdas por transporte, as quais ocorrem sob a forma

Foco da produção em massa

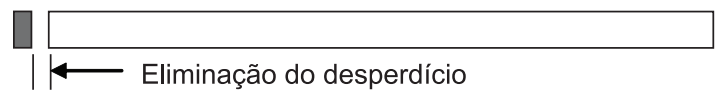

Foco da produção enxuta

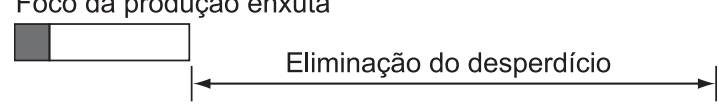

Figura 2. Focos das produções em massa e enxuta segundo Hines e Taylor (2000). Fonte: Araújo (2004, p. 33). de transportes desnecessários sofridos pelas matérias-primas, materiais em processo e produtos acabados. As melhorias mais significativas em termos de redução das perdas por transporte são aquelas obtidas por meio da eliminação das necessidades de transporte. Sendo assim, as melhorias dos equipamentos de transporte devem ser introduzidas somente depois de esgotadas todas as possibilidades de eliminação das necessidades de transporte.

- O quarto grupo de desperdício é o das perdas por processamento, as quais ocorrem sob a forma de processamentos desnecessários que não criam valor para o cliente. As melhorias mais significativas em termos de redução das perdas por processamento são aquelas obtidas por meio da eliminação das atividades que não criam valor. Sendo assim, as melhorias das atividades que criam valor devem ser introduzidas somente depois de esgotadas todas as possibilidades de eliminação das atividades que não criam valor.

- O quinto grupo de desperdício é o das perdas por estoque, as quais ocorrem sob a forma de estoques desnecessários de matérias-primas, materiais em processo e produtos acabados. As empresas em massa utilizam a elevação gradativa dos estoques para esconder os problemas, enquanto as empresas enxutas, no sentido contrário, utilizam a redução gradativa dos estoques para expor os problemas.

- O sexto grupo de desperdício é o das perdas por movimentação, as quais ocorrem sob a forma de movimentações desnecessárias realizadas pelos operadores. As melhorias mais significativas em termos de redução das perdas por movimentação são aquelas obtidas por meio da racionalização dos movimentos. Sendo assim, as melhorias de automação devem ser introduzidas somente depois de terem sido esgotadas todas as possibilidades de racionalização dos movimentos.

- O sétimo grupo de desperdício é o das perdas por produção de produtos defeituosos, as quais ocorrem sob a forma de produções de produtos defeituosos que não atendem às especificações dos clientes. As melhorias mais significativas em termos de redução das perdas por produção de produtos defeituosos são aquelas obtidas por meio da aplicação sistemática de métodos de controle junto à causa raiz das anormalidades. 
Para eliminar os desperdícios e, principalmente, suas fontes, as empresas enxutas utilizam-se do pensamento enxuto. De acordo com Queiroz, Araújo e Rentes (2004), a essência do pensamento enxuto é a eliminação do desperdício onde ele existir. Womack e Jones (1998) definem o pensamento enxuto como uma forma de especificar valor, alinhar na melhor sequência as atividades que criam valor e realizá-las sem interrupção e de forma cada vez mais eficaz toda vez que alguém as solicita.

\section{Contabilidade de custos}

Segundo Martins (2003), para o propósito de custeio dos produtos, todo gasto deve ser classificado de acordo com sua função em custos ou despesas. Custos são todos os gastos associados diretamente à produção dos produtos e subdividem-se em custos de materiais diretos (CMD), custos de mão de obra direta (CMOD) e custos indiretos de fabricação (CIF). Despesas são todos os gastos não associados diretamente à produção dos produtos e subdividemse em despesas administrativas (DA), despesas de vendas (DV) e despesas financeiras (DF).

Ainda de acordo com Martins (2003), outra classificação importante para o propósito de custeio dos produtos é aquela que faz a separação dos custos em fixos ou variáveis. Custos fixos (CF) são aqueles que dentro de um intervalo relevante de tempo são constantes em relação às variações no volume de produção, sendo representados pelos CIF, enquanto custos variáveis $(\mathrm{CV})$ são aqueles que dentro de um intervalo relevante de tempo variam em proporção direta às variações no volume de produção, sendo representados pelos CMD e pelos CMOD.

Pamplona (1997) destaca que os três principais métodos de custeio encontrados nas empresas são o por absorção, o variável e o baseado em atividades, apresentados a seguir.

\subsection{Custeio por absorção}

De acordo com Martins (2003), no custeio por absorção todos os custos são atribuídos aos produtos, ou seja, os CMD, os CMOD e os CIF, e somente estes, ficando, portanto, excluídas as despesas, tratadas como gastos do período.

Para o autor, no custeio por absorção a tomada de decisão é realizada com base no conceito de lucro unitário (Lu), calculado pela diferença entre o preço unitário $(\mathrm{Pu})$ e o custo unitário $(\mathrm{Cu})$ (Equação 1):

$$
L u=P u-C u
$$

resultando que (Equação 2):

$$
L u=P u-(C M D u+C M O D u+C I F u)
$$

uma vez que o Cu é dado pela soma dos custos de material e de mão de obra diretos, bem como dos custos indiretos de fabricação.

Segundo Pamplona (1997), no custeio por absorção, o produto será atrativo quando apresentar $\mathrm{Lu}>0$, e quanto maior o Lu do produto, mais atrativo ele será para a empresa.

De acordo com Martins (2003), no custeio por absorção, a atribuição dos CIF ocorre em dois estágios. No primeiro, os CIF são atribuídos diretamente aos departamentos de produção ou, então, são atribuídos inicialmente aos departamentos de serviços e, posteriormente, destes aos de produção. Neste primeiro estágio, a atribuição dos CIF é feita por meio do rateio com base tanto em medidas volumétricas, como por exemplo, as horas de mão de obra direta, quanto em medidas não volumétricas, como por exemplo, a área ocupada. No segundo, os CIF atribuídos aos departamentos de produção são, agora, atribuídos aos produtos. Neste segundo estágio, a atribuição dos CIF é feita por meio do rateio com base somente em medidas volumétricas, sobretudo, as horas de mão de obra direta.

Pamplona (1997), no entanto, alerta que a atribuição dos CIF por meio do rateio com base em medidas volumétricas, sobretudo, com base nas horas de mão de obra direta, apresenta um grave problema.

A Figura 3 desenvolvido por Miller e Vollmann e apresentado por Pamplona (1997) ajuda a entender o problema.

Para Goldratt (1991), quando o custeio por absorção faz a atribuição dos CIF por meio do rateio com base em medidas volumétricas, ele está, erroneamente, considerando que tais custos variam de modo direto às variações em tais medidas.

Martins (2003), porém, chama a atenção para o fato de que quando o custeio por absorção foi estabelecido, o rateio com base em medidas

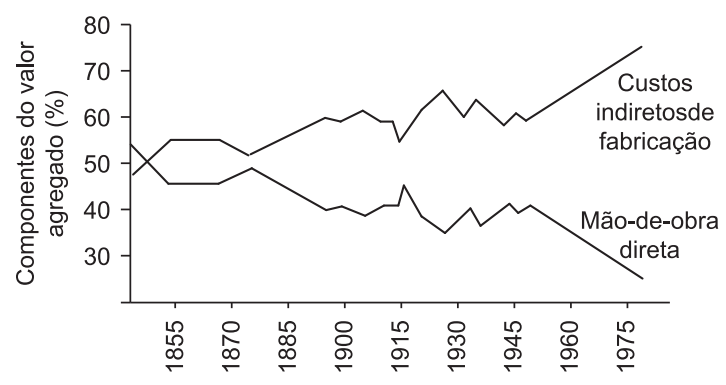

Figura 3. Participação dos CIF no custo total apresentada por Miller e Vollmann. Fonte: Pamplona (1997, p. 16). 
volumétricas fazia todo sentido, uma vez que os erros ficavam restritos a uma parcela muito pequena dos custos totais.

A Figura 3, no entanto, mostra que o composição dos custos mudou drasticamente, passando os CIF a representar a parcela mais significativa dos custos totais.

Para Pamplona (1997), embora seja inquestionável que os CIF passaram a representar a parcela mais significativa dos custos totais, verifica-se, ainda, que de um modo geral, permanece nas empresas a atribuição dos CIF pelo rateio com base em medidas volumétricas, o que amplia, agora, os erros à parcela mais significativa dos custos totais.

Pamplona (1997) aprofunda a discussão em torno das horas de mão de obra direta, base volumétrica de rateio mais utilizada pelas empresas. Para o autor, o custo dos produtos das linhas com mão de obra intensiva é sobrecarregado com os CIF originados pelas linhas altamente automatizadas, fazendo com que tais produtos pareçam menos ou, até mesmo, não lucrativos. Pamplona (1997) encerra concluindo que toda esta discussão conduz a uma conclusão bastante desastrosa, ou seja, a de que muitas linhas de produtos podem ser abandonadas em função de informações incorretas fornecidas pelo custeio por absorção.

\subsection{Custeio variável}

De acordo com Martins (2003), no custeio variável, somente os custos diretos são atribuídos aos produtos, ou seja, aos CMD e aos CMOD, e somente a estes, ficando, portanto, excluídos os CIF e as despesas, tratados como gastos do período.

Para o autor, no custeio variável a tomada de decisão é realizada com base no conceito de margem de contribuição unitária $(\mathrm{MCu})$, calculada pela diferença entre o preço unitário $(\mathrm{Pu})$ e o custo variável unitário $(\mathrm{CVu})$ (Equação 3):

$$
M C u=P u-C v u
$$

resultando que (Equação 4):

$$
M C u=P u-(C M D u+C M O D u)
$$

uma vez que o CVu é dado pela soma dos custos de material e de mão de obra diretos.

Segundo Pamplona (1997), no custeio variável, o produto será atrativo quando apresentar $\mathrm{MCu}>0$, e quanto maior a $\mathrm{MCu}$ do produto, mais atrativo ele será para a empresa.

Ainda de acordo com Pamplona (1997), a tomada de decisão no custeio variável é mais precisa que a tomada de decisão no custeio por absorção, o que se explica pelo fato do custeio variável atribuir somente os custos diretos aos produtos, eliminando, portanto, a necessidade de rateio dos CIF e, consequentemente, sua imprecisão.

\subsection{Custeio baseado em atividades}

De acordo com Spedding e Sun (1999), o custeio baseado em atividades - ABC surgiu ao longo da década de 1980 como alternativa ao custeio por absorção e, desde então, tem sido utilizado estrategicamente pelas empresas como uma importante ferramenta de apoio à tomada de decisão.

Segundo Pamplona (1997), as atividades representam o foco do ABC e, sendo assim, identificá-las e classificá-las é o primeiro passo.

O primeiro grupo identificado por Pamplona (1997) é o das atividades primárias, definidas aquelas atividades consumidas diretamente pelos produtos.

O segundo grupo identificado por Pamplona (1997) é o das atividades secundárias, definidas como aquelas atividades consumidas por outras atividades.

Uma vez que todas as atividades estejam devidamente identificadas e classificadas, pode-se dar início ao custeio dos produtos, que ocorrem em três etapas, apresentadas a seguir, definidas pelo próprio Pamplona (1997).

A primeira etapa de aplicação do ABC definida por Pamplona (1997) é representada pelo rastreamento dos custos dos recursos às atividades consumidoras daqueles por meio dos direcionadores de recursos.

A segunda etapa de aplicação do ABC definida por Pamplona (1997) é representada pelo rastreamento dos custos das atividades secundárias às primárias consumidoras daquelas pelos direcionadores de atividades.

A terceira etapa de aplicação do ABC definida por Pamplona (1997) é representada pelo rastreamento dos custos das atividades primárias aos produtos consumidores daquelas pelos direcionadores de atividades.

Para Martins (2003), no ABC, a tomada de decisão é realizada com base no conceito de lucro unitário $(\mathrm{Lu})$, calculado pela diferença entre preço unitário $(\mathrm{Pu})$ e custo unitário $(\mathrm{Cu})$ (Equação 5):

$$
L u=P u-C u
$$

de onde resulta que (Equação 6): 


$$
L u=P u-(C M D u+C M O D u+C I F u)
$$

uma vez que o $\mathrm{Cu}$ é dado pela soma dos custos de material e de mão de obra diretos, bem como dos custos indiretos de fabricação.

Segundo Pamplona (1997), no ABC, o produto será atrativo quando apresentar $\mathrm{Lu}>0$, e quanto maior o $\mathrm{Lu}$ do produto, mais atrativo ele será para a empresa.

Ainda de acordo com Pamplona (1997), os direcionadores de recursos e de atividades estabelecem uma relação do tipo causa e efeito entre os custos e os seus consumidores, conferindo ao $\mathrm{ABC}$ maior precisão quando comparado aos métodos tradicionais, sobretudo, tratando-se do custeio por absorção.

\section{Contabilidade de ganhos}

Goldratt (1991) afirma que qualquer sistema tem pelo menos uma restrição que limita seu desempenho, o que o levou a criar o processo de otimização contínua da TOC para as restrições físicas.

A primeira etapa da otimização contínua da TOC para as restrições físicas desenvolvida por Goldratt (1991) é identificar a(s) restrição(ões) do sistema.

Goldratt (1991) explica que em um sistema sempre haverá uma restrição que limitará o seu desempenho, assim como em uma corrente sempre haverá um elo fraco que limitará a sua resistência. Para aumentar o desempenho do sistema, deve-se identificar o seu elo mais fraco. Quando isto for alcançado, a próxima etapa da otimização contínua da TOC fica óbvia, ou seja, ao colocar as mãos nas coisas que limitam o desempenho do sistema, é fundamental não desperdiçar nada delas.

Assim, a segunda etapa da otimização contínua da TOC para as restrições físicas desenvolvida por Goldratt (1991) é decidir como explorar a(s) restrição(ões) do sistema.

Goldratt (1991) explica que o recurso que limita o desempenho do sistema foi identificado na etapa anterior. Qualquer minuto perdido neste recurso implica em um minuto perdido no sistema, e para aumentar o desempenho do sistema é necessário explorar ao máximo este recurso. Quando isto for alcançado, a próxima etapa da otimização contínua da TOC fica óbvia, ou seja, é fundamental garantir que os recursos não restritivos abasteçam as restrições somente com as quantidades necessárias e quando necessárias.
Assim, a terceira etapa da otimização contínua da TOC para as restrições físicas desenvolvida por Goldratt (1991) é subordinar tudo o mais à decisão anterior.

Goldratt (1991) explica que os recursos não restrição não podem trabalhar mais devagar que a restrição, pois, assim, ela pararia e o desempenho do sistema seria afetado negativamente. Por outro lado, não devem trabalhar mais rápido que a restrição, pois, assim, não estariam aumentando a produção do sistema, mas, somente, o estoque em processo. Para aumentar o desempenho do sistema, deve-se fazer com que as não restrições trabalhem no passo das restrições, nem mais rápido e, também, nem mais devagar. Quando isto for alcançado, a próxima etapa da otimização contínua da TOC fica óbvia, ou seja, é fundamental buscar um modo de reduzir o impacto causado pelas restrições. Afinal, elas não são um ato definitivo.

Assim, a quarta etapa da otimização contínua da TOC para as restrições físicas desenvolvida por Goldratt (1991) é elevar a(s) restrição(ões) do sistema.

Goldratt (1991) explica que na segunda etapa, buscou-se explorar o máximo possível das restrições. Nesta etapa, serão consideradas as várias alternativas para investir mais nas restrições. Para aumentar o desempenho do sistema é necessário quebrar as suas restrições. Quando isto é alcançado, a próxima etapa da otimização contínua da TOC fica óbvia, ou seja, é fundamental voltar à primeira etapa.

Assim, a quinta etapa da otimização contínua da TOC para as restrições físicas desenvolvida por Goldratt (1991) é que, se na etapa 4 uma restrição foi quebrada, volte à etapa 1 , mas não deixe que a inércia cause uma restrição de política no sistema.

Goldratt (1991) explica que, se na etapa 4 uma restrição foi quebrada, volte à etapa 1 e identifique a(s) nova(s) restrição(ões) do sistema a partir da nova realidade, mas não deixe que a inércia cause uma restrição de política no sistema.

Corbett Neto (1997) afirma que, para uma empresa melhorar seu desempenho, ela deve administrar suas restrições, o que exige medidas de desempenho coerentes com a meta da empresa.

Segundo Goldratt (1991), a meta da empresa é ganhar mais dinheiro agora e no futuro. Sendo assim, para poder julgar o impacto de qualquer ação local sobre a meta da empresa, três perguntas devem ser respondidas. A primeira é: quanto dinheiro é gerado pela empresa? A segunda é: quanto dinheiro 
é capturado pela empresa? A terceira é: quanto dinheiro é gasto pela empresa para operá-la? A transformação destas perguntas resulta nas três medidas de desempenho intuitivamente óbvias da TOC desenvolvidas por Goldratt (1991).

A primeira medida de desempenho da contabilidade de ganhos desenvolvida por Goldratt (1991) é o ganho (G), índice pelo qual a empresa gera dinheiro por meio das vendas, calculado como o preço $(\mathrm{P})$ menos os custos totalmente variáveis (CTV), estes restritos, geralmente, aos CMD. Na contabilidade de ganhos, é o mercado quem impõe o preço às empresas. Além disto, o G não pode ser associado à manobra interna de dinheiro na empresa, daí as palavras adicionais "por meio das vendas", pois material produzido e não vendido não gera $G$ para a empresa (Equação 7):

$$
G=P-C T V
$$

sendo o $\mathrm{G}$ da empresa dado pelo somatório dos $\mathrm{G}$ individuais de todas as unidades de todos os tipos de produtos da empresa.

A segunda medida de desempenho da contabilidade de ganhos desenvolvida por Goldratt (1991) é o inventário (I), que representa todo o dinheiro que a empresa investe em coisas que pretende vender. $\mathrm{O}$ termo "I" no lugar do "ativo" é proposital, pois, o único valor possível de ser atribuído aos estoques de matérias-primas, materiais em processo e produtos acabados, é o valor pago aos fornecedores pelos materiais. Isto significa que não há valor agregado aos produtos, nem mesmo o da MOD, pois durante a produção, só se agregam custos. O único momento em que de fato se agrega valor à empresa é o da realização das vendas.

A terceira medida de desempenho da contabilidade de ganhos desenvolvida por Goldratt (1991) é a despesa operacional (DO), que representa todo o dinheiro que a empresa gasta transformando I em G. O conceito de DO inclui todo o gasto realizado no período, independente da realização das vendas, como os salários e os benefícios tanto da mão de obra direta quanto indireta, a depreciação, etc.

De acordo com o próprio Goldratt (1991), estas três medidas são suficientes para julgar o impacto de qualquer ação local sobre a meta da empresa, e o ideal é que qualquer ação local aumente o $\mathrm{G}$ e diminua o I e a DO, ou, ainda, que aumente o LL e o retorno sobre o investimento (RSI), definidos também por Goldratt (1991) e reapresentados pelas Equações 8 e 9:

$$
\begin{gathered}
L L=G-D O \\
R S I=L L / I
\end{gathered}
$$

\section{Contabilidade de custos $v$. contabilidade de ganhos}

Goldratt (1991) e Corbett Neto (1997) fazem uma comparação entre os pressupostos do mundo dos custos e do mundo dos ganhos.

No mundo dos custos, a escala de prioridade é dada pela sequência DO, G e I, demonstrando que o mundo dos custos tem como medida principal o custo da empresa, medido pela soma dos custos de cada uma de suas atividades. Com isto, uma redução dos custos em qualquer atividade é vista como uma redução dos custos de toda a empresa. Fazendo a analogia com uma corrente, é como se a medida principal fosse o seu peso, o que implica que qualquer melhoria em qualquer elo seja vista como uma melhoria de todo o sistema, ou seja, basta reduzir o peso de qualquer elo. Portanto, o pressuposto do mundo dos custos é o de que as otimizações locais isoladas conduzem à otimização global da empresa. Enquanto a redução dos custos for considerada a principal via de acesso à meta da empresa, a percepção prevalecente será a de que qualquer aprimoramento em qualquer atividade é um aprimoramento de toda a empresa.

No mundo dos ganhos, a escala de prioridades é dada pela sequência G, I e DO, pois afinal, sendo a meta da empresa ganhar mais dinheiro agora e no futuro, só há uma opção para a otimização contínua: o limite para a redução dos custos é zero e, sendo assim, esta opção não possibilita a otimização contínua. Já o limite para o aumento do G é infinito e, sendo assim, esta opção possibilita a otimização contínua. Portanto, o mundo dos ganhos tem como medida principal o G. Em seguida, é importante destacar que os inventários de materiais em processo e produtos acabados têm impacto negativo sobre o G, uma vez que, quanto maiores os inventários, maiores serão o lead time e o tempo de resposta ao mercado, com expressivo prejuízo às vendas agora e no futuro. Portanto, o mundo dos ganhos tem como segunda medida mais importante o I. Fazendo a analogia com uma corrente, é como se a medida principal fosse a sua resistência. Isto faz com que a maioria das melhorias na maioria dos elos não melhore todo o sistema, ou seja, é necessário aumentar a resistência do elo mais fraco. Portanto, o pressuposto do mundo dos ganhos é o de que as otimizações locais isoladas não conduzem à otimização global da empresa. Enquanto o aumento do $\mathrm{G}$ for considerado a principal via de acesso à meta da empresa, a percepção prevalecente será a de que a maioria dos aprimoramentos na maioria das atividades não é um aprimoramento de toda a empresa. 
O exemplo desenvolvido por Corbett Neto (1997), e apresentado logo em seguida, demonstra as diferenças quanto à tomada de decisão nos mundos dos custos e dos ganhos.

Considere uma empresa contendo somente dois produtos, $\mathrm{P}$ e Q. O potencial de mercado e o preço de venda de $\mathrm{P}$ e $\mathrm{Q}$ são, respectivamente, de 100 e de 50 unidades por semana e de $\mathrm{R} \$ 90$ e $\mathrm{R} \$ 100$ por unidade. $O$ preço da peça e das matérias-primas 1 , 2 e 3 (MP1, 2 e 3 ) são, respectivamente, de $\mathrm{R} \$ 5$ e de $\mathrm{R} \$ 20$ por unidade.

Em cada recurso existe somente um único operador e não há intercambiabilidade, ou seja, A não pode fazer o trabalho de $\mathrm{B}, \mathrm{C}$ ou $\mathrm{D}$ e vice-versa. Além do mais, cada recurso e cada operador fica disponível cinco dias por semana e oito horas por dia. Por fim, o set up é definitivamente igual a zero, o que, consequentemente, resulta em uma disponibilidade em cada recurso de 2400 minutos por semana.

A DO da empresa é de $\mathrm{R} \$ 6$ mil por semana, a qual inclui os salários e os benefícios tanto da mão de obra direta quanto da indireta, a depreciação e tudo mais que a empresa gasta transformando I em G. O que não está incluído na DO da empresa é, definitivamente, o dinheiro pago aos fornecedores pela peça e pelas MP1, 2 e 3, pois este é I, uma vez que é dinheiro que a empresa investe em coisas que pretende vender.

A Figura 4 apresenta os dados referentes aos recursos.

$\mathrm{P}$

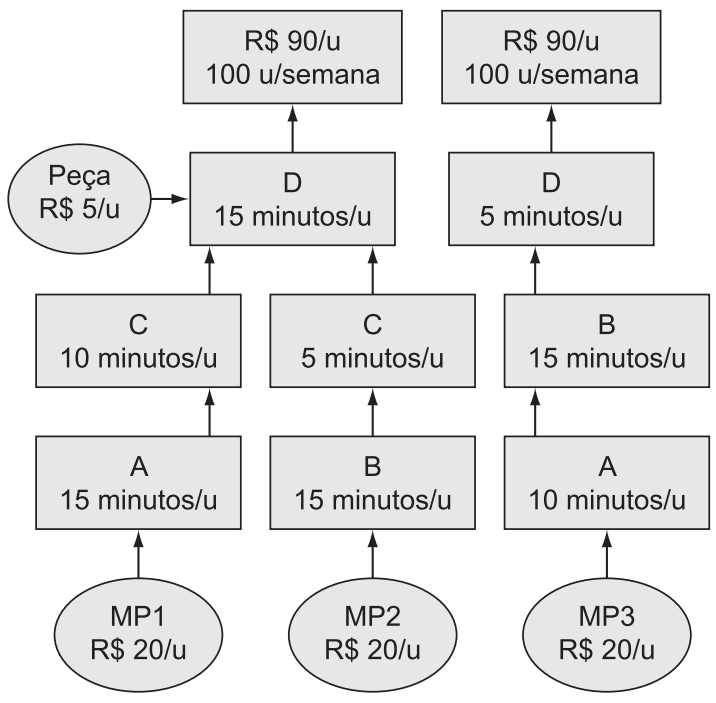

Figura 4. Entendendo a tomada de decisão na contabilidade de ganhos. Fonte: Goldratt (1991, p.76).

\section{a) Tomada de decisão no mundo dos custos}

O primeiro passo é calcular o G gerado pelo produto P. Para cada uma das 100 unidades por semana que podem ser vendidas deste produto, os clientes estão dispostos a pagar R \$ 90. Porém, multiplicando-se estes dois números obtém-se as vendas, não o G. Para calculá-lo, é necessário subtrair do preço de venda o montante pago aos fornecedores, que, neste caso, é de R $\$ 45$. Portanto, o G gerado pelo produto $\mathrm{P}$ é de $\mathrm{R} \$ 4,5$ mil por semana. O segundo passo é calcular o $G$ gerado pelo produto Q. Para cada uma das 50 unidades por semana que podem ser vendidas deste produto, os clientes estão dispostos a pagar $\mathrm{R} \$ 100$. Porém, multiplicando-se estes dois números obtêm-se, mais uma vez, as vendas, não o G. Para calculá-lo, é necessário subtrair do preço de venda o montante pago aos fornecedores, que, neste caso, é de $\mathrm{R} \$ 40$. Portanto, o G gerado pelo produto Q é de $\mathrm{R} \$ 3$ mil por semana. O terceiro passo é calcular o $\mathrm{G}$ total, dado pelo somatório dos $\mathrm{G}$ individuais, $\mathrm{R} \$ 4,5$ mil mais $\mathrm{R} \$ 3$ mil, de onde resultam R\$ 7,5 mil por semana. Obviamente, este é o G, não o LL. Para calculá-lo, é necessário subtrair do G a DO. Portanto, o LL é de R \$ 7,5 mil menos R \$ 6 mil, de onde resultam R $\$ 1,5$ mil por semana. Tudo muito direto e tudo muito errado, pois as pessoas não seguem sua intuição, mas o seu treinamento.

De acordo com a otimização contínua da TOC para as restrições físicas, o primeiro passo ao abordar qualquer sistema é identificar a(s) sua(s) restrição(ões) e, para isto, é necessário comparar a carga com a disponibilidade em cada recurso. Para o recurso A, a carga estabelecida pelo produto $P$ é de 100 unidades por semana vezes 15 minutos por unidade, de onde resultam 1500 minutos por semana. Adicionalmente, a carga estabelecida pelo produto Q é de 50 unidades por semana vezes 10 minutos por unidade, de onde resultam 500 minutos por semana. Portanto, a carga total é de 2000 minutos por semana, contra uma disponibilidade de 2400 , de onde se conclui que tal recurso é uma não restrição. Para o recurso $\mathrm{B}$, a carga estabelecida pelo produto $\mathrm{P}$ é de 100 unidades por semana vezes 15 minutos por unidade, de onde resultam 1500 minutos por semana. Adicionalmente, a carga estabelecida pelo produto $\mathrm{Q}$ é de 50 unidades por semana vezes 30 minutos por unidade, de onde resultam 1500 minutos por semana. Portanto, a carga total é de 3000 minutos por semana, contra uma disponibilidade de 2400, de onde se conclui que tal recurso é uma restrição. Para o recurso C, a carga estabelecida pelo produto $\mathrm{P}$ é de 100 unidades por semana vezes 15 minutos por unidade, de onde resultam 1500 minutos por semana. Adicionalmente, a carga estabelecida pelo produto $\mathrm{Q}$ é de 50 unidades por semana vezes 5 minutos por unidade, de onde resultam 250 minutos por 
semana. Portanto, a carga total é de 1750 minutos por semana, contra uma disponibilidade de 2400 , concluindo-se que tal recurso é uma não restrição. Para o recurso $D$, a carga estabelecida pelo produto $P$ é de 100 unidades por semana vezes 15 minutos por unidade, de onde resultam 1500 minutos por semana. Adicionalmente, a carga estabelecida pelo produto Q é de 50 unidades por semana vezes 5 minutos por unidade, de onde resultam 250 minutos por semana. Portanto, a carga total é de 1750 minutos por semana, contra uma disponibilidade de 2400 , concluindo-se que tal recurso é uma não restrição.

Após analisar cada um dos recursos, fica claro que é impossível satisfazer todo o potencial de mercado, pois não há capacidade suficiente do recurso $\mathrm{B}$, o que obriga a empresa a decidir quais produtos e em quais quantidades oferecer.

Muitos gerentes que não caem na primeira armadilha e alcançam este ponto concluem que deve ser oferecido o produto mais lucrativo. Porém, a definição do produto mais lucrativo pode ser realizada sob diferentes pontos de vista. Primeiro, pelo preço de venda, e, neste caso, o produto $\mathrm{P}$ é vendido por R $\$ 90$ a unidade, enquanto o produto $\mathrm{Q}$ é vendido por $\mathrm{R} \$ 100$ a unidade. Portanto, o produto Q é o mais lucrativo. Segundo, pelo CTV, e, neste caso, o produto $\mathrm{P}$ consome um CTV de $\mathrm{R} \$ 45$ por unidade, enquanto o produto Q consome um CTV de $\mathrm{R} \$ 40$ por unidade. Portanto, o produto $\mathrm{Q}$ é o mais lucrativo. Terceiro, pelo $\mathrm{G}$, e, neste caso, o produto $\mathrm{P}$ gera um $\mathrm{G}$ de $\mathrm{R} \$ 45$ por unidade, enquanto o produto $\mathrm{Q}$ gera um $\mathrm{G}$ de $\mathrm{R} \$ 60$ por unidade. Portanto, o produto Q é o mais lucrativo. Quarto, pela MOD, $\mathrm{e}$, neste caso, o produto $\mathrm{P}$ consome 60 minutos de MOD por unidade, enquanto o produto $Q$ consome 50 minutos de MOD por unidade. Portanto, o produto Q é o mais lucrativo. Concluindo-se, então, que os diferentes pontos de vista conduzem sempre à mesma resposta, ou seja, a de que, qualquer que seja o sistema de custos utilizado, o produto Q é sempre o mais lucrativo.

Utilizando as conclusões anteriores como orientação, deve-se, agora, determinar quais produtos e em quais quantidades oferecer. Começando, naturalmente, pelo produto mais lucrativo, ou seja, o $\mathrm{Q}$, tem-se que podem ser vendidas 50 unidades por semana deste produto, sendo que cada uma destas unidades consome 30 minutos da restrição. Portanto, a carga estabelecida pelo produto Q é de 50 unidades por semana vezes 30 minutos por unidade, de onde resultam 1500 minutos por semana. Por outro lado, a disponibilidade é de 2400 minutos por semana. Deste modo, sobram somente 900 minutos para serem utilizados na produção do produto P. E como cada uma das unidades do produto $\mathrm{P}$ consome 15 minutos da restrição, conclui-se que é possível produzir e oferecer somente 60 unidades semanais deste produto. Logo, o melhor mix que se pode oferecer é 50 unidades do produto $\mathrm{Q}$ mais 60 unidades do produto $\mathrm{P}$, ambos, naturalmente, por semana. Porém, a única maneira de julgar se a contabilidade de custos conduz à decisão correta é calculando o LL.

O G gerado pelo produto Q é de 50 unidades por semana vezes $R \$ 60$ por unidade, de onde resultam R\$ 3 mil por semana. Adicionalmente, o G gerado pelo produto $P$ é de 60 unidades por semana vezes $\mathrm{R} \$ 45$ por unidade, de onde resultam $\mathrm{R} \$ 2,7 \mathrm{mil}$ por semana. Portanto, o G total é de R 3 mil mais $\mathrm{R} \$ 2,7$ mil de onde resultam $\mathrm{R} \$ 5,7$ mil por semana. Obviamente, este é o G, não o LL. Para calculá-lo, é necessário subtrair do G a DO. Portanto, o LL é de $\mathrm{R} \$ 5,7$ mil menos $\mathrm{R} \$ 6$ mil, de onde resultam $-\mathrm{R} \$ 300$ por semana, o que significa que a empresa vai perder $\mathrm{R} \$ 300$ por semana.

Acontece que este último cálculo não está de acordo com o mundo dos ganhos, pois somente usar a terminologia das restrições não é o suficiente. É necessário ir além e se livrar dos bloqueios mentais plantados pelo mundo dos custos. Para uma empresa melhorar o seu desempenho, ela deve administrar suas restrições e, neste assunto, não há escolha. De acordo com a otimização contínua da TOC para as restrições físicas, o segundo passo ao abordar qualquer sistema é decidir como explorar a(s) sua(s) restrição(ões).

A tomada de decisão no mundo dos ganhos demonstra as implicações das etapas do processo de otimização contínua da TOC para as restrições físicas.

\section{b) Tomada de decisão no mundo dos ganhos}

Cada unidade do produto $P$ tem um $G$ de $R \$$ 45 e consome 15 minutos da restrição. Portanto, quando se oferece uma unidade do produto $\mathrm{P}$, obtém-se R\$ 3 de $G$ por minuto da restrição. Cada unidade do produto $\mathrm{Q}$ tem um $\mathrm{G}$ de $\mathrm{R} \$ 60$ e consome 30 minutos da restrição. Portanto, quando se oferece uma unidade do produto P, obtêm-se R $\$ 2$ de G por minuto da restrição.

Utilizando as conclusões anteriores como orientação, deve-se, agora, determinar quais produtos e em quais quantidades oferecer. Começando, naturalmente, pelo produto com o maior $\mathrm{G}$ por unidade da restrição, ou seja, o P, tem-se que podem ser vendidas 100 unidades por semana deste produto, sendo que cada uma destas unidades consome 15 minutos da restrição. Portanto, a carga estabelecida pelo produto $\mathrm{P}$ é de 100 unidades por semana vezes 15 minutos por unidade, de onde resultam 1500 minutos por semana. Por outro 
lado, a disponibilidade é de 2400 minutos por semana. Deste modo, sobram somente 900 minutos para serem utilizados na produção do produto Q. E como cada uma das unidades do produto $\mathrm{Q}$ consome 30 minutos da restrição, conclui-se que é possível produzir e oferecer somente 30 unidades semanais deste produto. Logo, o melhor mix que se pode oferecer é 100 unidades do produto $P$ mais 30 unidades do produto $\mathrm{Q}$, ambos, naturalmente, por semana. Porém, a única maneira de julgar se a contabilidade de ganhos conduz à decisão correta é calculando o LL.

O G gerado pelo produto $P$ é de 100 unidades por semana vezes $\mathrm{R} \$ 45$ por unidade, de onde resultam $\mathrm{R} \$ 4,5$ mil por semana. Adicionalmente, o $\mathrm{G}$ gerado pelo produto $Q$ é de 30 unidades por semana vezes $\mathrm{R} \$ 60$ por unidade, de onde resultam $\mathrm{R} \$ 1,8$ mil por semana. Portanto, o $\mathrm{G}$ total é de $\mathrm{R} \$ 4,5$ mil mais $\mathrm{R} \$ 1,8$ mil, de onde resultam $\mathrm{R} \$ 6,3$ mil por semana. Obviamente, este é o G, não o LL. Para calculá-lo, é necessário subtrair do G a DO. Portanto, o LL é de $\mathrm{R} \$ 6,3$ mil menos $\mathrm{R} \$ 6$ mil, de onde resultam $\mathrm{R} \$ 300$ por semana, o que significa que a empresa vai ganhar $\mathrm{R} \$ 300$ por semana.

\subsection{Inadequação da contabilidade de custos à produção enxuta}

De acordo com Corbett Neto (1997), a contabilidade de custos não é capaz de prover as informações necessárias à correta tomada de decisão. Para o autor, deve-se entender como contabilidade de custos o custeio por absorção, o custeio variável, o $\mathrm{ABC}$ ou, ainda, qualquer outra metodologia que tenha custos como base, uma vez que todas, sem exceção, repousam sobre o mesmo pressuposto equivocado da produção em massa, ou seja, o de que as otimizações locais isoladas conduzem à otimização global. Em uma empresa, a utilização deste pressuposto equivocado se reflete nos medidores de eficiência das máquinas, pois todos tentam maximizar a eficiência de todas as máquinas, não podendo haver ociosidade em nenhum lugar. Porém, uma empresa sempre tem recursos com menor capacidade que outros, o que faz com que a procura por elevadas eficiências locais isoladas só conduza ao aumento dos estoques de material em processo, como pode ser demonstrado com a ajuda da Figura 5.
Segundo Corbett Neto (1997), o recurso C é um recurso com restrição de capacidade (RRC) e, sendo assim, ao perseguir $100 \%$ de eficiência local no recurso B, por exemplo, a empresa estará aumentando seus desperdícios e seus custos, sem que, em contrapartida, esteja aumentando os seus ganhos, pois estes são limitados pelo RRC.

É possível, então, concluir que as medidas de eficiências locais isoladas, apregoadas pela contabilidade de custos, não conduzem à eficiência global da empresa, mas sim, ao desperdício, o que contraria os princípios da produção enxuta.

\subsection{Maior e melhor adequação da contabilidade de ganhos à produção enxuta}

A contabilidade de custos tem como pressuposto que as otimizações locais isoladas conduzem à otimização global da empresa. É por isto que a contabilidade de custos busca as otimizações locais isoladas e julga o impacto de qualquer ação local sobre o resultado local, algo que estimula a superprodução e contradiz os princípios da produção enxuta

Já a contabilidade de ganhos tem como pressuposto que as otimizações locais isoladas não conduzem à otimização global da empresa. É por isto que a contabilidade de ganhos busca a otimização global da empresa e julga o impacto de qualquer ação local sobre o resultado global da empresa, sendo ideal que qualquer ação local aumente o G e diminua o I e a DO, ou, ainda, que aumente o LL e o RSI, algo que desestimula a superprodução e reafirma os princípios enxutos.

\subsubsection{Contabilidade de ganhos vs. custeio variável}

Jones e Dugdale (1998) defendem que a contabilidade de ganhos não apresenta grandes inovações ao modelo de apuração do lucro, uma vez que as ideias sobre os conceitos de custo variável e de margem de contribuição estão presentes nos livros de contabilidade de custos há muitos anos.

Já Goldratt (1991) e Corbett Neto (1997) defendem que o custeio variável e a contabilidade de ganhos têm objetivos muito diferentes, uma vez que o
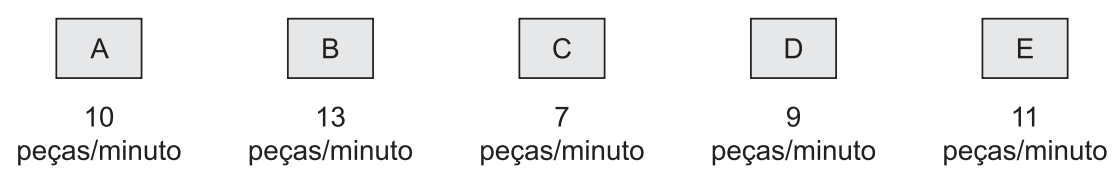

Figura 5. Linha de produção simples. Fonte: Corbett (1997, p. 114). 
objetivo do custeio variável são as otimizações locais isoladas, enquanto que o objetivo da contabilidade de ganhos é a otimização global da empresa.

Ainda segundo os autores, um dos principais argumentos contra o custeio variável é o de que ele não se preocupa com os custos fixos. Neste ponto, a contabilidade de ganhos é bem diferente, pois para cada ação local, é necessário quantificar o impacto sobre o G e a DO, para com isto, verificar se o LL e o RSI vão aumentar ou não.

\subsubsection{Contabilidade de ganhos vs. custeio baseado em atividades}

Noreen, Smith e Mackey (1996), Kee e Schmidt (2000) e Lea e Fredendall (2002), citam que certos autores defendem que contabilidade de ganhos e ABC têm prazos diferentes. $O$ conceito de curto prazo $v$ s. longo prazo se baseia na capacidade de produção. No curto prazo, assume-se que a capacidade de produção é fixa e não pode ser mudada facilmente, o que, inevitavelmente, irá criar restrições. Para os autores, neste contexto, os pressupostos da contabilidade de ganhos fazem sentido. No longo prazo, assumese que mais e mais custos irão se tornar variáveis quando a capacidade de produção for ajustada. Para os autores, neste contexto, os pressupostos do $\mathrm{ABC}$ fazem sentido.

Corbett Neto (1997) concorda que os custos são mesmos variáveis no longo prazo, e que ignorar esta variabilidade não é correto. No entanto, o autor também afirma que não é correto pensar que é necessário calcular os custos de longo prazo dos produtos para se poder tomar as decisões corretas, pois, afinal, no longo prazo a empresa ainda continuará sendo um sistema e, portanto, ainda continuará tendo o seu desempenho limitado por suas restrições. Para o autor, quando a contabilidade de custos afirma que é necessário calcular os custos de longo prazo dos produtos, ela está, na prática, defendendo a ideia de que no longo prazo a empresa não terá restrições, e, que por isto, todos os seus recursos serão igualmente importantes. Segundo o autor, é como defender que no longo prazo as otimizações locais isoladas não subordinadas à otimização global da empresa irão fazer sentido, o que não é correto.

Para Goldratt (1991), os custos da empresa variam somente quando é necessário aumentar a quantidade daquilo do qual não se tem o suficiente, ou seja, quando é necessário elevar as restrições da empresa. Segundo o autor, é possível aumentar o desempenho sem aumentar os custos. Para isto, é necessário somente explorar ao máximo as restrições.
Trata-se da necessidade da mudança do mundo dos custos para o mundo dos ganhos.

\section{Conclusões}

Constata-se que a contabilidade de custos, síntese maior dos sistemas de gestão econômica voltados para a produção em massa, não é capaz de prover as informações necessárias à correta tomada de decisão nas empresas enxutas. A incapacidade da contabilidade de custos em apoiar o processo decisório nas empresas enxutas ocorre, sobretudo, pelo fato de ela calcular os custos dos produtos como a soma dos custos de todas as atividades necessárias para produzi-los e entregá-los. A realização desta soma faz com que a contabilidade de custos considere todos os recursos como igualmente importantes, sejam eles restrições ou não restrições, o que é incorreto, como muito bem demonstra a contabilidade de ganhos, braço contábil da Teoria das Restrições.

De acordo com a contabilidade de ganhos, toda empresa é um sistema e todo sistema tem pelo menos uma restrição que determina sua capacidade e limita seu desempenho. Sendo assim, é necessário que a empresa identifique as suas restrições e decida como explorá-las, de tal modo que as restrições e as não restrições sejam tratadas de modo diferente, estando as não restrições subordinadas às restrições. A implicação do tratamento diferenciado entre as restrições e as não restrições é que o pressuposto da contabilidade de custos de que as otimizações locais isoladas conduzem à otimização global da empresa é substituído pelo pressuposto da contabilidade de ganhos que sempre julga o impacto de qualquer ação local sobre o resultado global da empresa.

Confrontando os pressupostos do mundo dos custos e do mundo dos ganhos com os princípios enxutos, conclui-se que existe uma maior e melhor adequação da contabilidade de ganhos à produção enxuta. A maior e melhor adequação da contabilidade de ganhos à produção enxuta deve-se, sobretudo, ao fato da contabilidade de ganhos desestimular o maior dos desperdícios combatidos pela produção enxuta, que é a superprodução. O desestímulo à superprodução na contabilidade de ganhos decorre do fato desta, ao contrário da contabilidade de custos, que vê no aumento dos volumes de produção, tanto das restrições quanto das não restrições, uma forma de reduzir os custos unitários, considerar que material produzido e não vendido não aumenta o ganho da empresa, causando somente aumentos nos seus inventários e nas suas despesas operacionais. Com isto, conclui-se que a falta de habilidade em administrar suas restrições faz que as empresas enxutas que continuam aplicando a contabilidade 
de custos não consigam avaliar adequadamente seus resultados, comprometendo, até mesmo, a própria continuidade da implementação enxuta.

\section{Agradecimentos}

À Coordenação de Aperfeiçoamento de Pessoal de Nível Superior/CAPES pelo apoio financeiro concedido por meio de uma bolsa de doutorado.

\section{Referências}

ARAÚJO, C. A. C. Desenvolvimento e aplicação de um método para implementação de sistemas de produção enxuta utilizando os processos de raciocínio da teoria das restrições e o mapeamento do fluxo de valor. 2004. 143 f. Dissertação (Mestrado) - Universidade de São Paulo, São Carlos, 2004.

CORBETT NETO, T. Contabilidade de ganhos: a nova contabilidade gerencial de acordo com a teoria das restrições. São Paulo: Nobel, 1997.

GHINATO, P. Elementos fundamentais do sistema Toyota de produção. In: ALMEIDA, A. T.; SOUZA, F. M. C. Produção e competitividade: aplicações e inovações. Recife: UFPE, 2000. p. 31-59.

GOLDRATT, E. M. A síndrome do palheiro: garimpando informação num oceano de dados. São Paulo: Educator, 1991.

HINES, P.; TAYLOR, D. Going lean: a guide to implementation. Cardiff: Lean Enterprise Research Center, 2000.

JONES, T. C; DUGDALE, D. Theory of constraints: transforming ideas? British Accouting Review, v. 30, n. 1, p. 73-91, 1998.
KEE, R.; SCHMIDT, C. A comparative analysis of utilizing activity-based costing and the teory of constraints for making product-mix decisions. International Journal of Productions Economics, v. 63, n. 1, p. 1-17, 2000.

LEA, B. R.; FREDENDALL, L. D. The impact of management accounting, product structure, product mix algorithm, and planning horizon on manufacturing performance. International Journal of Production Economics, v. 79, n. 1, p. 279-299, 2002.

MARTINS, E. Contabilidade de custos. São Paulo: Atlas, 2003.

NOREEN, E.; SMITH, D.; MACKEY, J. T. A Teoria das restrições e suas implicações na contabilidade gerencial: um relatório independente. São Paulo: Educator, 1996.

PAMPLONA, E. O. Contribuição para análise crítica do sistema de custos $\mathrm{ABC}$ através da avaliação de direcionadores de custos. 1997. 167 f. Tese (Doutorado) Fundação Getúlio Vargas, São Paulo, 1997.

QUEIROZ, J. A.; ARAÚJO, C. A. C.; RENTES, A. F. Transformação enxuta: aplicação do mapeamento do fluxo de valor em uma situação real. In: ENCONTRO NACIONAL DE ENGENHARIA DE PRODUÇÃO ENEGEP, 24., 2004, Santa Catarina. Anais... Florianópolis: Abepro, 2004.

ROTHER, M.; SHOOK, J. Aprendendo a enxergar: mapeando o fluxo de valor para agregar valor e eliminar o desperdício. São Paulo: Lean Institute, 1999.

SPEDDING, T. A.; SUN, G. Q. Application of discrete event simulation to the activity based costing of manufacturing systems. International Journal of Production Economics, v. 58, n. 1, p. 289-301, 1999.

WOMACK, J. P.; JONES, D. A mentalidade enxuta nas empresas: elimine o desperdício e crie riqueza. Rio de Janeiro: Campus, 1998. 